\title{
EMF-33 insights on bioenergy with carbon capture and storage (BECCS)
}

\section{Matteo Muratori, et al. [full author details at the end of the article]}

Received: 1 October 2019 / Accepted: 29 June 2020 / Published online: 20Augus t2020

(C) Battelle Memorial Institute 2020

\begin{abstract}
This paper explores the potential role of bioenergy coupled to carbon dioxide $\left(\mathrm{CO}_{2}\right)$ capture and storage (BECCS) in long-term global scenarios. We first validate past insights regarding the potential use of BECCS in achieving climate goals based on results from 11 integrated assessment models (IAMs) that participated in the 33rd study of the Stanford Energy Modeling Forum (EMF-33). As found in previous studies, our results consistently project large-scale cost-effective BECCS deployment. However, we also find a strong synergistic nexus between CCS and biomass, with bioenergy the preferred fuel for CCS as the climate constraint increases. Specifically, the share of bioenergy that is coupled to CCS technologies increases since CCS effectively enhances the emissions mitigation capacity of bioenergy. For the models that include BECCS technologies across multiple sectors, there is significant deployment in conjunction with liquid fuel or hydrogen production to decarbonize the transportation sector. Using a wide set of scenarios, we find carbon removal to be crucial to achieving goals consistent with $1.5^{\circ} \mathrm{C}$ warming. However, we find earlier BECCS deployment but not necessarily greater use in the long-term since ultimately deployment is limited by economic competition with other carbon-free technologies, especially in the electricity sector, by land-use competition (especially with food) affecting biomass feedstock availability and price, and by carbon storage limitations. The extent of BECCS deployment varies based on model assumptions, with BECCS deployment competitive in some models below carbon prices of $100 \mathrm{US} \$ / \mathrm{tCO}_{2}$. Without carbon removal, $2{ }^{\circ} \mathrm{C}$ is infeasible in some models, while those that solve find similar levels of bioenergy use but substantially greater mitigation costs. Overall, the paper provides needed transparency regarding BECCS' role, and results highlight a strong nexus between bioenergy and CCS, and a large reliance on not-yet-commercial BECCS technologies for achieving climate goals.
\end{abstract}

Keywords Bioenergy · Negative emissions · Carbon capture and storage $\cdot$ CCS $\cdot$ BECCS $\cdot$ Carbon dioxide removal $\cdot$ Integrated assessment $\cdot$ Model comparison $\cdot$ EMF

This article is part of the special issue "Assessing Large-scale Global Bioenergy Deployment for Managing Climate Change (EMF-33)” edited by Steven Rose, John Weyant, Nico Bauer, Shinichiro Fuminori, Petr Havlik, Alexander Popp, Detlef van Vuuren, and Marshall Wise.

Electronic supplementary material The online version of this article (https://doi.org/10.1007/s10584-02002784-5) contains supplementary material, which is available to authorized users. 


\section{Introduction}

Integrated assessment models (IAMs) are used to generate future global energy, land, and economic transformation pathways consistent with climate change mitigation goals (e.g., Clarke et al. 2014). Bioenergy with carbon capture and storage (BECCS) is one of the main technology solutions included in IAMs to remove carbon dioxide from the atmosphere and provide "negative emissions" (Kemper 2015; Rose et al. 2014; Koelbl et al. 2014; van Vliet et al. 2014; Rogelj et al. 2015; van Vuuren et al. 2013; Calvin et al. 2009). Many IAM scenarios rely heavily upon BECCS as a means to provide negative emissions, effectively removing $\mathrm{CO}_{2}$ from the atmosphere and permanently sequestering it. Bioenergy with $\mathrm{CCS}$ can be coupled with multiple energy or industrial uses including electricity, liquid fuels, and hydrogen production (Muratori et al. (2017b)). For a detailed overview of alternative negative emission technologies see NAS (2018) and Smith et al. (2016). Such negative emissions are used in IAMs predominantly in the second half of the century allowing for more gradual nearterm emissions reductions while staying within cumulative emissions budgets (recovering from cumulative emissions budget overshoots) (Clarke et al. 2014; Rogelj et al. 2018) and to offset emissions from sectors that are projected to be harder to decarbonize, such as transportation (Muratori et al. 2017a).

However, while BECCS is seen as a least-cost emissions reduction strategy in IAMs, BECCS technologies are not commercially available today, and the viability and economic consequences of large-scale BECCS deployment are not fully understood. Carbon capture and sequestration (CCS) technologies have not been deployed as fast as projections had envisioned (Bui et al. 2018). Likewise, several studies have raised concerns about the institutional and technical limitations of scenarios involving large-scale BECCS deployment, suggesting that before IAM scenarios using BECCS can be confidently relied upon, further evaluation of BECCS assumptions and implementation strategies should be undertaken (Tavoni and Socolow 2013; Fuss et al. 2014; Vaughan and Gough 2016; Muratori et al. 2016; Sanchez and Kammen 2016; Strefler et al. 2018).

This paper reports results of the 33rd study of the Stanford Energy Modeling Forum (EMF33) model intercomparison study focusing on the role of BECCS in different climate change mitigation and technology assumption scenarios designed to compare results and develop insights related to BECCS deployment from different IAMs. We find that negative emissions are essential in EMF-33 scenarios to limit warming to $1.5{ }^{\circ} \mathrm{C}$, and large-scale BECCS deployment is projected across multiple sectors with limited long-term sensitivity to climate change mitigation goals and uncertainties in BECCS costs. Rather, BECCS deployment is limited by modeling assumptions, physical limitations (land use, carbon storage), and economic competition with other carbon-free technologies, especially in the electricity sector, which affect bioenergy availability and price. A strong nexus between CCS and biomass is shown consistently across models.

Earlier studies have looked at the use of BECCS in IAMs. In almost all of these studies, BECCS was the only carbon dioxide removal (CDR) technology available, so that the shown reliance on BECCS could be interpreted as a reliance on CDR in general. For instance, Koelbl et al. (2014) analyzed the long-term role of CCS technologies in the EMF-27 study, showing that IAMs consistently rely on BECCS under stringent climate targets. A similar insight was found in the EMF-27 study exploring the deployment of bioenergy in general (Rose et al. 2014). Azar et al. (2010) investigate the technological and economic attainability of meeting climate targets using three global energy system models (IMAGE/TIMER, GET, and 
MESSAGE), concluding that BECCS significantly enhances the possibility to meet low concentration targets. Azar et al. (2013) use the GET model to show that temperature targets can be met at considerably lower cost if BECCS is available and that BECCS makes it feasible to reach temperature targets that are otherwise out of reach, provided that a temporary overshoot of the target is acceptable. Edmonds et al. (2013) show with the GCAM model that while a variety of technology scenarios that do not include BECCS could be consistent with the $2{ }^{\circ} \mathrm{C}$ goal, BECCS can potentially reduce the cost of achieving this target. Edmonds et al. (2013) also find the value of BECCS to be substantially higher under delayed action. Muratori et al. (2016) use the GCAM model to explore the nexus between BECCS, the carbon price required to mitigate climate change, and the value of bioenergy (including food commodities), concluding that BECCS availability results in reduced climate change mitigation costs and decreased pressure on food prices. Klein et al. (2014) explore the use of bioenergy for achieving stringent climate stabilization targets using the REMIND-MAgPIE model concluding that BECCS is a crucial mitigation option with high deployment levels and high technology value. A review by Fuss et al. (2018) quantified the lower end of CDR costs at $\$ 100$ per $\mathrm{tCO}_{2}$. Gasser et al. (2015) use earth system models, rather than IAMs, to provide a physical lower bound of negative emission requirements consistent with the $2{ }^{\circ} \mathrm{C}$ target concluding that negative emissions are required at significant levels ( $>1 \mathrm{Gt} \mathrm{C}$ per year).

In the EMF-33 study, 11 IAM models have run a set of mitigation scenarios specifically focusing on bioenergy. With this focus, the study offers a unique opportunity to compare BECCS deployment across IAMs with a set of consistent scenarios and climate change mitigation goals. The present study builds on and extends the EMF-27 study that highlighted the importance of BECCS in the energy sector for achieving stringent mitigation targets. EMF33 includes a broad set of specific scenarios to test the role of bioenergy strategies for climate change mitigation. The BECCS results and insights from the EMF-33 study are presented and evaluated in this paper.

\section{Methods}

\subsection{Modeling BECCS technologies: assumptions and model representation}

All 11 IAMs considered in this paper include BECCS technologies. These technologies are the only source of net-negative emissions (or CDR) included in the models for energy-related emissions, although some models also include land-use-based negative emissions options such as afforestation. BECCS technologies in different models can be deployed in different sectors and models use different technology assumptions (see Daioglou et al. 2020, this issue). Table 1 summarizes the availability of BECCS technologies in different IAMs participating to EMF-33 across the main energy conversion sectors. All models include BECCS technologies coupled to electricity generation. However, BECCS coupled to hydrogen and liquid fuels production are only included in some models (respectively, biomass can be gasified to produce hydrogen, or further processed into liquid fuels using the Fischer-Tropsch process. Both processes can be coupled to CCS), and only IMAGE includes BECCS technologies in an additional sector (industrial heat). The different assumptions of technology availability across sectors limit the range of BECCS deployment and, thus, strongly influence IAM results.

More detailed model descriptions for each model can be found in their respective model documentations (see Bauer et al. 2018 for specific references). Cost and performance 


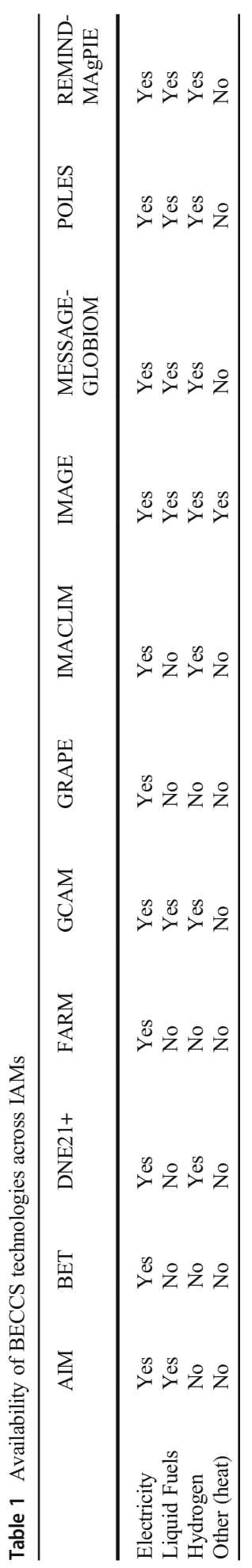


assumptions (i.e., efficiency and capture rate) for BECCS technologies in different sectors and their evolution over time (including considerations on endogenous learning or exogenously specified changes over time) are described in Daioglou et al. 2020 (this issue). Modeling of biomass feedstock supply is described in Rose et al. 2020 (this issue).

\subsection{Scenarios}

The EMF-33 study considers several scenarios, described in detail in Bauer et al. 2018 (this issue) that cover a wide range of climate change mitigation objectives, technology assumptions, and bioenergy constraints. For the purpose of this paper, we consider nine scenarios (Table 2), with scenario naming consisting of three elements: type of climate policy $(\mathrm{B}=$ cumulative carbon budget, with carbon prices computed endogenously in each model to meet this constraint); level of ambition (high, low, very low); and bioenergy technology availability (full, the full complement of default technologies - bioenergy and nonbioenergy related - as modeled in each IAM, delayed in time, more expensive, or not available). EMF-33 scenarios mainly focus on bioenergy deployment and emission mitigation in the energy and industry sectors. IAMs differ considerably regarding the representation of land-use sector and corresponding GHG emissions. The influence of biomass feedstock production and carbon pricing on land-use emissions in EMF-33 is studied in Rose et al. 2020 (this issue). The carbon budgets account for energy and industry $\mathrm{CO}_{2}$ emissions and net of carbon removals due to BECCS. All other GHG emissions (or sinks), including land use emissions and $\mathrm{CO}_{2}$ removals from afforestation and other land-use changes are not accounted for in the carbon budgets considered here. These GHG emissions and removals, however, are priced at the same rate as $\mathrm{CO}_{2}$ emissions and removals in the energy and industry sectors. This implies that carbon pricing consistently affects also the biomass feedstock supply costs and considers direct and indirect land-use change emissions. See Rose et al. 2020 (this issue) for discussion of the impacts of carbon pricing on biomass supply and land-use.

Table 2 Scenarios considered in this paper

\begin{tabular}{|c|c|c|c|c|c|}
\hline \multirow[t]{2}{*}{ Scenario* } & \multirow{2}{*}{$\begin{array}{l}\text { Climate change } \\
\text { mitigation policy }\end{array}$} & \multicolumn{3}{|c|}{ Advanced bioenergy technology availability } & \multirow{2}{*}{$\begin{array}{l}\text { Bioenergy } \\
\text { supply } \\
\text { limit }\end{array}$} \\
\hline & & BECCS & Cellulosic fuels & Hydrogen & \\
\hline B-hi-full & $1600 \mathrm{Gt} \mathrm{CO} 2$ budget & Yes & Yes & Yes & No \\
\hline B-lo-full & $1000 \mathrm{Gt} \mathrm{CO}$ budget & Yes & Yes & Yes & No \\
\hline B-vlo-full & $400 \mathrm{Gt} \mathrm{CO} 2$ budget & Yes & Yes & Yes & No \\
\hline B-hi-ready 2050 & $1600 \mathrm{Gt} \mathrm{CO} \mathrm{CO}_{2}$ budget & Not before 2050 & Not before 2050 & $\begin{array}{c}\text { Not before } \\
2050\end{array}$ & No \\
\hline B-lo-ready 2050 & $1000 \mathrm{Gt} \mathrm{CO} 2$ budget & Not before 2050 & Not before 2050 & $\begin{array}{c}\text { Not before } \\
2050\end{array}$ & No \\
\hline B-hi-cost100 & $1600 \mathrm{Gt} \mathrm{CO}_{2}$ budget & $\begin{array}{l}\text { With } 100 \% \\
\text { higher cost }\end{array}$ & $\begin{array}{l}\text { With } 100 \% \text { higher } \\
\text { cost }\end{array}$ & $\begin{array}{l}\text { With } 100 \% \\
\text { higher cost }\end{array}$ & No \\
\hline B-lo-cost100 & $1000 \mathrm{Gt} \mathrm{CO}_{2}$ budget & $\begin{array}{l}\text { With } 100 \% \text { higher } \\
\text { cost }\end{array}$ & $\begin{array}{l}\text { With } 100 \% \text { higher } \\
\text { cost }\end{array}$ & $\begin{array}{l}\text { With } 100 \% \\
\text { higher cost }\end{array}$ & No \\
\hline B-hi-nobeccs & $1600 \mathrm{Gt} \mathrm{CO}_{2}$ budget & No & Yes & Yes & No \\
\hline B-lo-nobeccs & $1000 \mathrm{Gt} \mathrm{CO} 2$ budget & No & Yes & Yes & No \\
\hline
\end{tabular}

* Scenario names consist of three elements: type of climate policy (B = cumulative carbon budget); level of ambition (high, low, very low); and bioenergy technology availability (full, as modeled in each IAM, delayed in time, more expensive, or not available) 


\section{Model intercomparison results}

\subsection{Scale and timing of potential use of BECCS}

Figure 1 illustrates the deployment of BECCS technologies over time (billion metric tons $\mathrm{CO}_{2}$ / year) across the different IAMs and scenarios with all advanced bioenergy technologies available as modeled. These results include BECCS used in all sectors and confirm earlier findings that BECCS technologies are deployed at large scale by most models in climate change mitigation scenarios, reflecting the cost-effectiveness of negative emissions relative to other emissions mitigation strategies. Generally, BECCS deployment starts after 2030, to different extents based on model assumptions and ambition of climate change mitigation goal. In the B-hi-full scenario all models project over $1 \mathrm{Gt} /$ year of $\mathrm{CO}_{2}$ captured using BECCS by 2050, with the exception of IMACLIM. Most models project over $10 \mathrm{Gt} /$ year of $\mathrm{CO}_{2}$ removal using BECCS by 2100. While long-term BECCS deployment in the B-lo-full scenario in 2100 is comparable with the B-hi-full scenario, it is approximately twice as large in 2050 compared with the less stringent climate change mitigation scenario, indicating a significantly more aggressive ramp-up in BECCS deployment in the first half of the century as the stringency of the climate change mitigation scenario increases (note that while global net $\mathrm{CO}_{2}$ emissions are still positive at this point in time in this scenario, the negative emissions technologies, BECCS, are already been deployed). Results for the B-vlo-full scenario show BECCS deployment ramping up even earlier compared with the B-lo-full scenario, but overall use of BECCS (for those models that could achieve the vlo target) is not significantly changed by further increasing the ambition of the climate change mitigation policy.

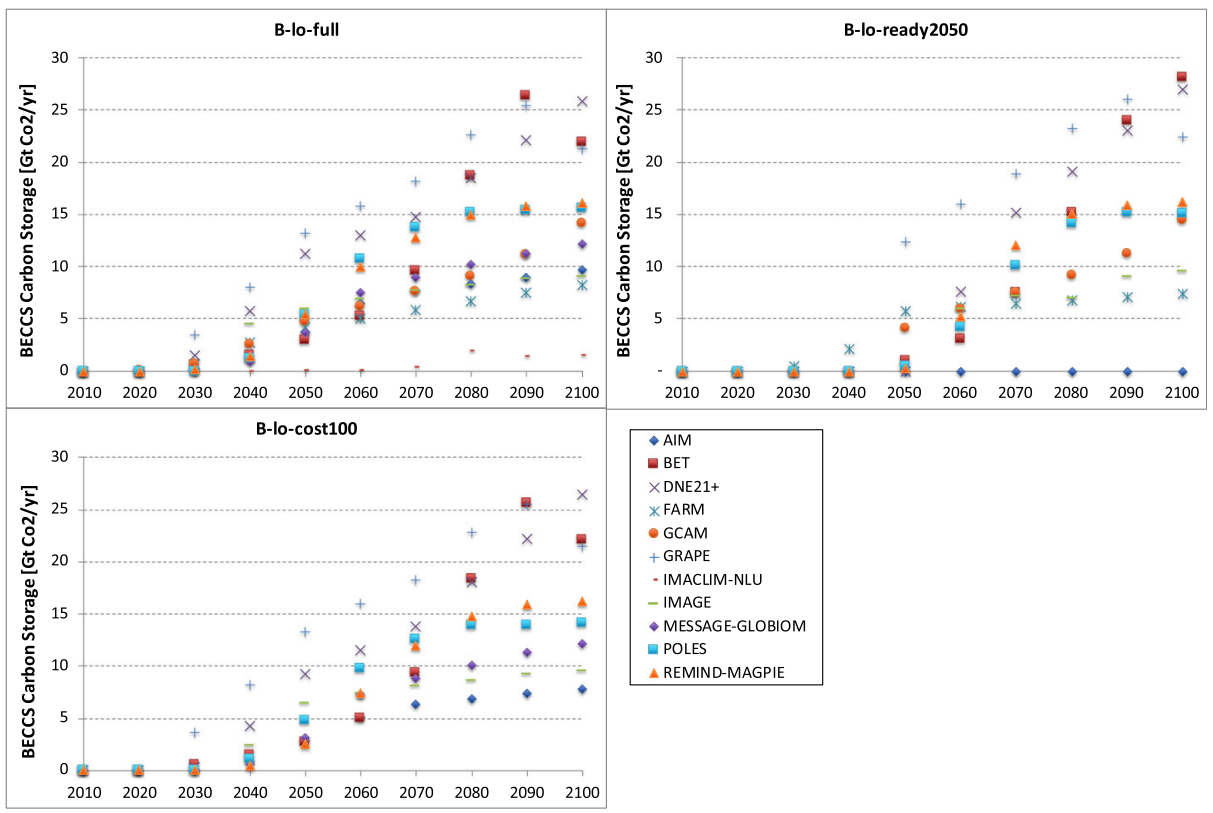

Fig. 1 Scale and timing of BECCS deployment for different climate change mitigation scenarios 
Alternative, more pessimistic, assumptions on BECCS technology availability and cost (ready2050 and cost100 scenarios) do not significantly change BECCS deployment in 2100 but delay slightly BECCS adoption over time and result in lower overall cumulative carbon captured for the higher carbon budget scenario (see Fig. S1). In the B-lo-cost100 scenario, however, doubling the cost of BECCS technologies does not significantly change BECCS deployed in 2050 (see Fig. S2). This is because the value of BECCS increases with the stringency of the scenario and demand for BECCS becomes increasingly insensitive to the technology cost (Daioglou et al. 2020, this issue).

The scale of BECCS deployment shown in Fig. 1 for the B-hi-full, B-lo-full, and B-vlo-full scenarios represents a significant share of total primary energy in these scenarios, as shown in Fig. 2. Models project up to almost $30 \%$ of primary energy involving BECCS technologies in 2050. Reliance on BECCS increases over time and as more stringent climate targets are considered. In most models, by 2100 in the B-lo-full scenario, BECCS technologies account for over $15 \%$ of total primary energy use, with some models reaching almost $50 \%$.

In the B-vlo-full scenario, all models project more than $20 \%$ of primary energy to be coupled to BECCS in 2100 , and one reaching nearly $60 \%$. These results confirm previous findings that, while currently not commercially available, in the absence of other CDR options BECCS is projected to play a major role in energy systems transformation pathways, especially in the second half of the century and for ambitious climate change mitigation targets. In particular, BECCS (here the only CDR technology considered) is shown to be potentially essential to reach the very low (vlo) climate target, with no model able to achieve the target without it (Table 3), while other constraints on bioenergy technologies may not be as binding on climate goals.

\subsection{Sectoral deployment of BECCS}

The results above report BECCS deployment as an aggregate, including all energy conversion sectors. While historically IAMs only considered BECCS technologies in conjunction with

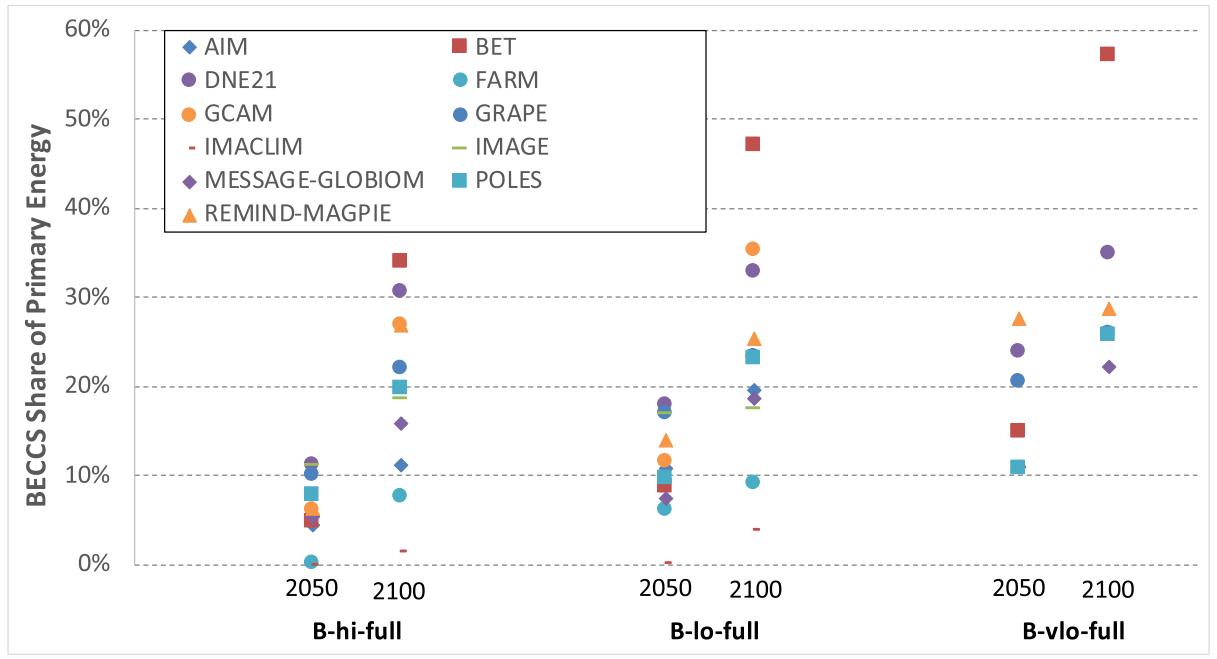

Fig. 2 BECCS share of primary energy for different climate change mitigation scenarios 
Table 3 Number of models solving for a particular scenario/models that tried to solve. Derived from Bauer et al. 2018

\begin{tabular}{lllllll}
$\begin{array}{l}\text { Full } \\
\text { technology }\end{array}$ & Cost100 & $\begin{array}{l}\text { Ready } \\
2050\end{array}$ & $\begin{array}{l}\text { No } \\
\text { lignocellulosic }\end{array}$ & $\begin{array}{l}\text { No } \\
\text { BECCS }\end{array}$ & $\begin{array}{l}\text { No } \\
\text { advanced } \\
\text { bioenergy } \\
\text { siomass } \\
\text { supply max } \\
100 \text { EJ/ } \\
\text { year }\end{array}$ \\
& & & & & & $\begin{array}{l}\text { Modern } \\
\text { biomar }\end{array}$ \\
$11 / 11$ & $10 / 10$ & $10 / 10$ & $11 / 11$ & $10 / 11$ & $10 / 11$ & $9 / 9$ \\
$11 / 11$ & $8 / 10$ & $7 / 9$ & $10 / 11$ & $6 / 11$ & $5 / 11$ & $8 / 9$ \\
$6 / 10$ & $6 / 10$ & $5 / 10$ & $5 / 10$ & $0 / 10$ & $0 / 10$ & $2 / 10$ \\
& & & & & & \\
\hline
\end{tabular}

electricity generation, Muratori et al. 2017b showed that BECCS deployment in liquid fuel production is a valuable strategy to mitigate transportation emissions, which tend to have limited mitigation options. Figure 3 shows the deployment of BECCS technologies by sector in 2050 and 2100 for the B-hi-full, B-lo-full, and B-vlo-full scenarios.

Result show that, for the models in which BECCS can be deployed across multiple sectors, there is significant deployment of BECCS for liquid fuel production (green bars), especially in GCAM, MESSAGE-GLOBIOM, and REMIND-MAgPIE (and the latter also project significant BECCS use for hydrogen production). Still, many models only include BECCS technologies in the electricity sector, as shown in Table 1, and the entire BECCS deployment is therefore coupled with power plants (orange bars in Fig. 3). The relative sectoral deployment
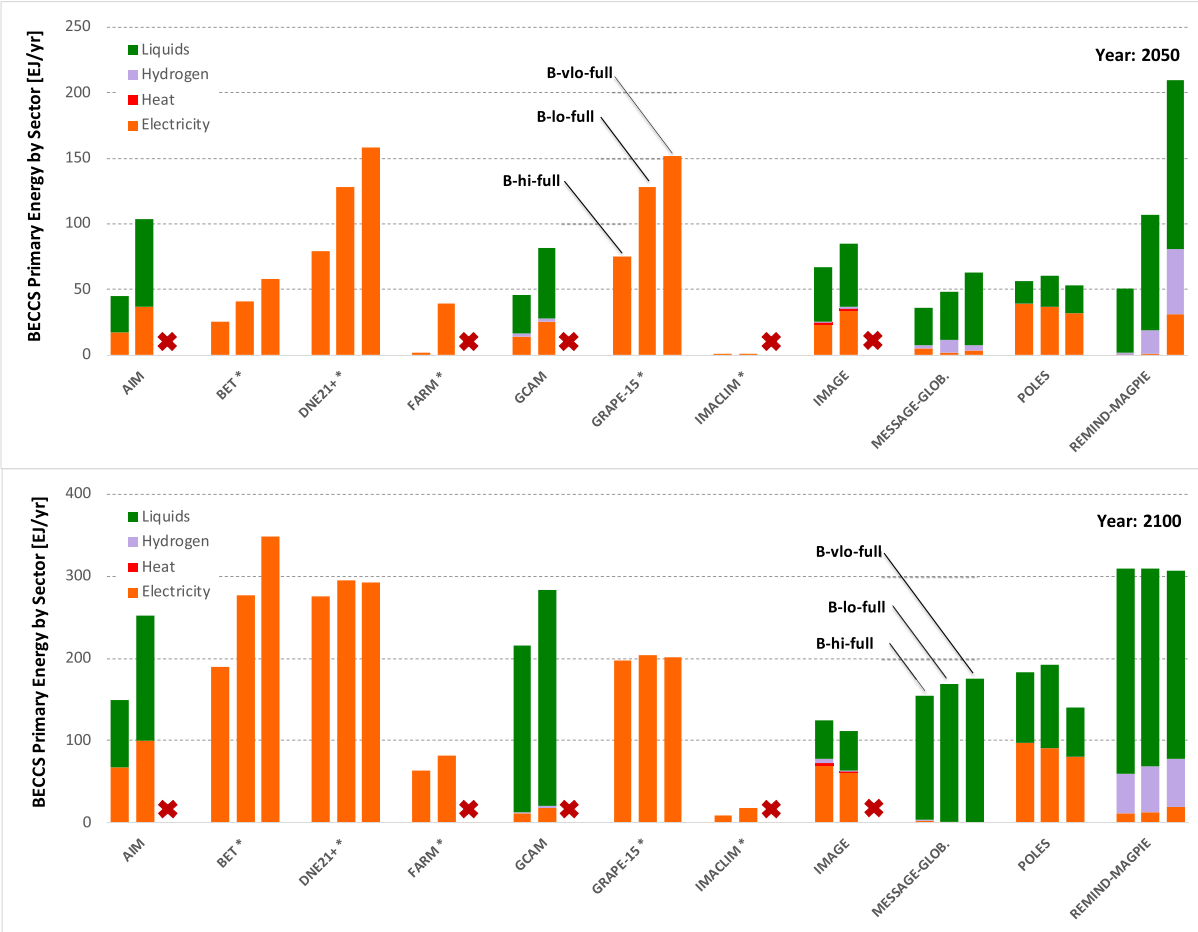

Fig. 3 BECCS deployment by sector (top panel for 2050, bottom panel for 2100). A red " $\mathrm{X}$ " indicates a scenario that could not be solved by a model and for which there are no results. * indicates models that do not include BECCS technology options for the production of liquid fuels (see Table 1) 
of BECCS technologies for each model is not significantly changed as a more stringent climate change mitigation goals are implemented. Also, BECCS deployment in the liquid fuel sector starts earlier compared with the electricity sector in most models, due to the limited availability of alternatives to mitigate transportation emissions from the transportation sector, especially for nonlight-duty vehicles (Leblanc et al. 2020 this issue), where liquid fuels are primarily used, and the relatively lower carbon abatement cost for BECCS coupled to liquid fuel production.

Delayed availability of BECCS technologies (ready2050 scenarios) does not significantly change overall BECCS deployment in 2100, both in terms of overall magnitude and sectoral deployment (see Fig. S3). Similarly, increased technology costs in the B-hi-cost100 scenarios delay BECCS adoption but do not significantly affect total and sectoral BECCS deployment in 2100. In the B-lo-cost100 scenario, however, the more stringent climate change mitigation target does not allow for deployment delays and, even with an $100 \%$ cost increase, BECCS sectoral technologies are deployed in 2050 at a similar scale compared with the B-lo-full scenario (except in the REMIND model).

The use of BECCS in the production of liquid fuels has been identified as a possible strategy to support the decarbonization of the transportation sector, especially for those subsectors with limited cost-competitive carbon-free fuel alternatives (e.g., aviation and freight in general, Muratori et al. 2017a). Figure 4 reports liquid fuels production by source, illustrating three main trends: first, the use of liquid fuels decreases with as the carbon price increases - liquid fuel secondary energy use decreases over time for all scenarios and as more stringent climate change mitigation target are considered. This is mainly due to reduced demand triggered by higher fuel prices and switching to other energy carriers that are easier to decarbonize (electricity and hydrogen). Second, as the carbon price increases, so does the

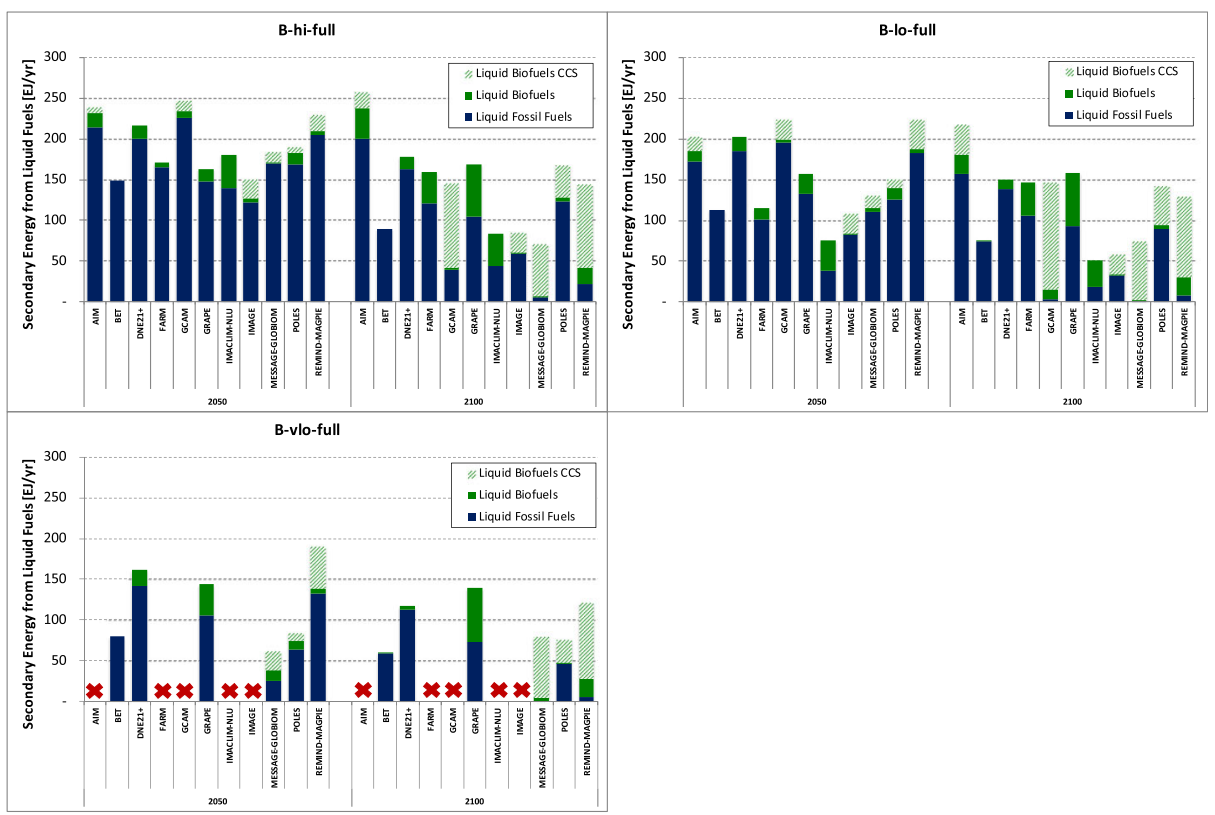

Fig. 4 Liquid fuels production (secondary energy) by source. A red " $\mathrm{X}$ " indicates a scenario that could not be solved by a model and for which there are no results 
relative share of liquid biofuels - more liquid fuels are produced starting from biomass rather than fossil fuels. Third, results show that, for those models for which producing liquid fuels with BECCS is an option, biofuels production coupled to CCS is usually preferred over simple biofuel production, even in 2050, mainly due to the relatively minor additional cost of CCS technologies for these applications compared with the carbon sequestration credits.

Figure 5 reports electricity production by source, highlighting other interesting trends. The total use of electricity increases significantly over time: an increase of 130-260\% from 2050 to 2100. The impact of the carbon price on total electricity production, however, is non-linear: compared with the B-hi-full scenario, the B-lo-full scenario shows slightly higher electricity use in 2050 and similar electricity use in 2100 (but electricity accounts for a larger share of total energy use). The B-vlo-full scenario shows reduced electricity use due to the stringent climate policy that makes energy in general more expensive. The electricity generation mix changes more significantly over time than for different carbon prices, due to assumed technology progress. In the B-hi-full scenario, fossil fuels without CCS still represent up to $22 \%$ of electricity generation in 2050 (13\% on average) while only POLES and GRAPE show $\sim 10 \%$ in 2100 . The use of fossil fuels with CCS increases in absolute terms from 2050 to 2100 , but generally decreases on a relative basis (share of primary energy). Nuclear energy increases over time across all models with very different final shares across models due to different technology assumptions (see Daioglou et al. 2020, this issue). Overall, renewable energy sources make up for the lion's share of electricity production increase and account for the majority of electricity production in most models already in 2050. Bioelectricity is mostly coupled to CCS (except for FARM). Models projecting lower shares of electricity from renewables (DNE21+ and GRAPE) rely more heavily on CCS, both in combination with fossil fuels and bioenergy. As more stringent climate change mitigation policies are considered

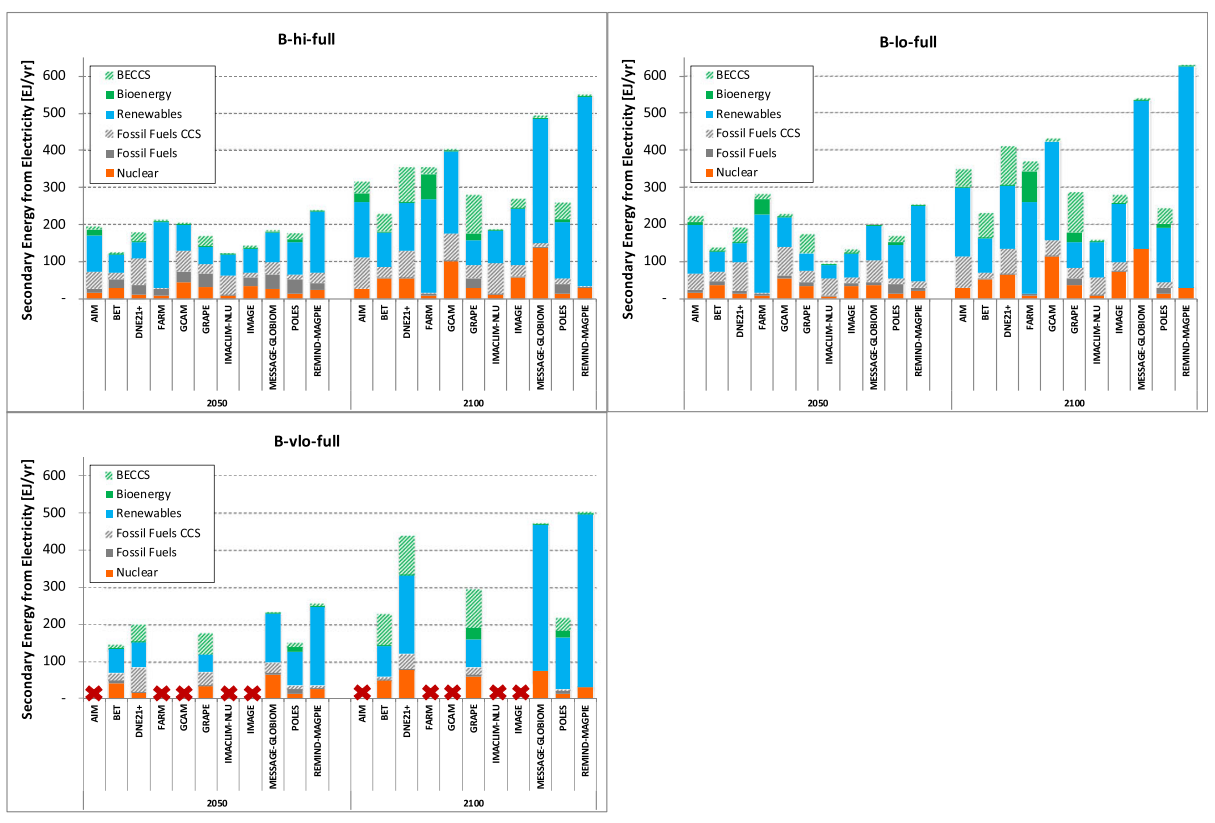

Fig. 5 Electricity production (secondary energy) by source. A red " $\mathrm{X}$ " indicates a scenario that could not be solved by a model and for which there are no results 
the electricity generation mix shows relative minor changes and BECCS deployment in the electricity sector is relatively inelastic to carbon prices compared with the liquid fuels sector.

It is important to note that technology adoption and deployment decisions in IAMs, such as those reported in Figs. 4 and 5, are based on multiple factors including technology availability, costs (relative to alternative options and considering demand elasticity), stock turnover and treatment of stranded assets, and other modeling assumptions. Daioglou et al. 2020 (this issue) conducted an assessment of the bioenergy technoeconomic specifications of the EMF-33 IAMs, showing significant variability in CCS assumptions. For instance, across models, adding CCS increases capital cost by $2-242 \%, 10-315 \%$, and $3-35 \%$ for electricity, liquids, and hydrogen, respectively. Similarly, the penalty on conversion efficiencies (percentage points) due to the integration of CCS ranges from 0 to $15 \%, 0$ to $10 \%$, and 0 to $12 \%$, respectively. Daioglou et al. 2020 (this issue) also show that the cost of the final bioenergy carriers is primarily driven by biomass feedstock costs and payments associated with negative emissions. Feedstock costs are the main (and most uncertain) cost component of bioenergy for technologies without CCS. For bioenergy technologies with CCS, payments from $\mathrm{CO}_{2}$ removal are more than offset feedstock and other costs.

However, it is important to stress that low-carbon investment decisions in IAMs, and thus differences in technology deployment across models, are not based only on costs. In particular, for BECCS technologies, while cost is an important determinant of deployment, a number of other factors determine implementation across different sectors, including transitional and system integration factors, as well as market dynamics. The most important dynamics, whose representations vary across IAMs, are fuel and biomass feedstock supply and costs, the relative elasticities of demand for different energy services, the availability and costs of alternative mitigation options for different end-uses, the availability and compensations related to $\mathrm{CO}_{2}$ removal options, including BECCS, and the speed at which large scale changes in the energy generation mix can take place. Moreover, other key assumption that some IAMs employ include limits on capacity expansion of innovative technologies, capital turnover of incumbent technologies, market share constraints for individual technologies, and in the case of CCS technologies, limitations on geological injection of $\mathrm{CO}_{2}$. All of these elements contribute to the differences found in the final energy mixes reported in Figs. 4 and 5.

\subsection{BECCS deployment: drivers and limiting factors}

In climate change mitigation scenarios, the $\mathrm{CO}_{2}$ emissions budget drivers the adoption of lowcarbon technologies in each model, and produces a carbon price that reflects the marginal value of the last unit of emissions avoided. In particular, BECCS deployment occurs with sufficiently high carbon prices (based on the full set of modeling assumptions discussed above), and, as the price of carbon rises, so does the value of BECCS due to the increasing value of negative emissions. The exact price at which models start deploying BECCS technologies, however, varies between models and emissions budgets, due to the different relative costs of available mitigation options in a year and over time and other modeling assumptions, as well as the need for reductions at each point in time, which varies by budget. BECCS deployment is influenced by a variety of factors and constraints and a higher carbon price does not necessarily translate into greater BECCS deployment. For instance, some models (e.g., IMACLIM-NLU, POLES) assume an upper bound on BECCS deployment that seems to reach an upper limit that is inelastic to further carbon price increases. Other models (e.g., GRAPE, BET) project a significant increase in BECCS deployment as the carbon price 
increases. Figure 6 illustrates the relationship between BECCS deployment over time and the carbon price. Models consistently start deploying BECCS technologies at carbon prices below $\$ 100 /$ ton $\mathrm{CO}_{2}$. Figure 6a shows results for carbon prices less than $\$ 100 / \mathrm{tCO}_{2}$ for the B-hi-full scenario (carbon prices generally exceed $\$ 100 / \mathrm{tCO}_{2}$ very early in other scenarios). Overall deployment of BECCS, however, varies significantly across models.

Deployment of BECCS technologies can be constrained by several factors, including (a) economic/market competition with other carbon-free technologies; (b) biomass feedstock availability; (c) carbon storage limitations (including total storage availability, storage cost increasing based on supply curves, and injection constraints); and (d) modeling limitations (e.g., limited capacity to deploy new technologies, technology choice effects, infrastructure or financial constraints, exogenous constraints). In all the models considered in this study, BECCS deployment is limited by economic competition with other carbon-free technologies, especially in the electricity sector, and by land-use competition (especially with food) affecting biomass availability and price. For REMIND-MAgPIE, constraints on geological carbon storage injection rates represent a key limitation to BECCS deployment in these scenarios (see Bauer et al. 2020 for more details and a sensitivity analysis around this assumption). For some IAMs, other modeling assumptions play a significant role in limiting BECCS deployment, including maximum technology market share growth rates (IMACLIM, AIM), capacity expansion constraints (REMIND-MAgPIE), or limits to $\mathrm{CO}_{2}$ transport capacity expansion. The area of land suitable for growing energy crops is also usually limited in each modeled region, with land use productivity differing across regions. Similarly, technoeconomic

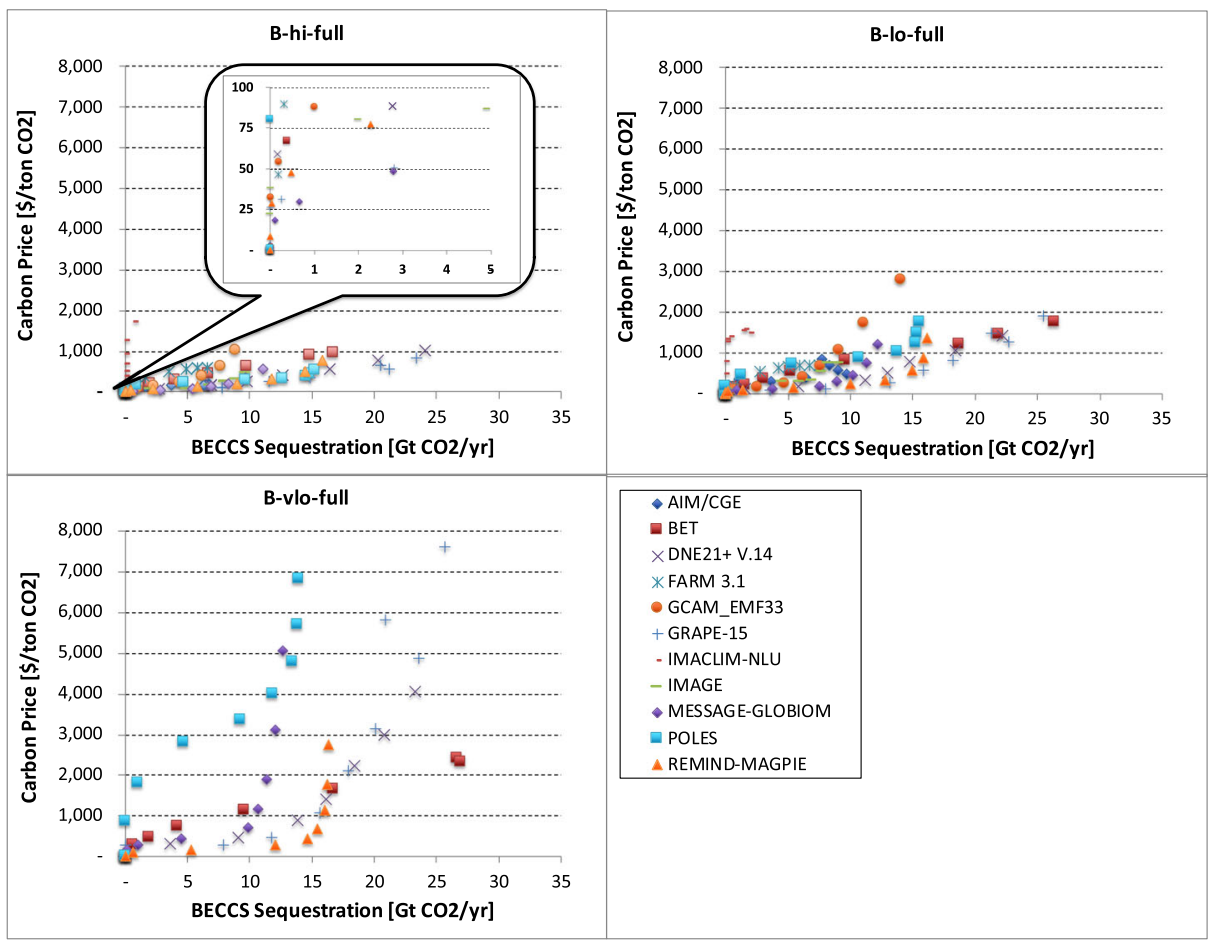

Fig. 6 Relationship between BECCS deployment and carbon price 
parameters might differ for different regions (see Daioglou et al. 2020, this issue). However, supply curves (e.g., for carbon storage availability and cost) are usually fixed in time, but technology characteristics, land productivity, and other modeling constraints usually vary over time.

Feasible scenarios that do not include BECCS technologies (B-hi-nobeccs and B-lo-nobeccs), illustrate that BECCS technologies are a key technology for stringent climate change mitigation objectives. These scenarios consistently show higher carbon prices compared with their sister scenarios with BECCS: on average over twice as high in 2050 and $~ 3$ times higher in 2100 for the high carbon budget, and over 4 times higher in 2050 and $\sim 7$ times higher in 2100 for the low carbon budget. Recall from Table 3 that no model was able to produce a solution for the most stringent carbon budget (vlo) without BECCS. The unavailability of BECCS technologies also influences deployment of other technologies, including lower use of liquid fuels ( $20 \%$ less in the high carbon budget scenario) and larger use of electricity (on average, electricity consumption increases by $10 \%$ in 2050 and $11 \%$ in 2100 for the high carbon budget scenario and 32\% in 2050 and $10 \%$ in 2100 for the low carbon budget scenario). The electricity generation mix is also influenced by the lack of BECCS technologies. Interestingly, the "no-BECCS" scenarios still project large-scale use of bioenergy and large-scale deployment of CCS with fossil fuels. Thus, bioenergy and CCS separately might still be important to a decarbonized future, even if not as a combined negative emissions technology (with possible BECCS restrictions based on exogenous assumptions representing institutional barriers).

Previous studies have identified a strong nexus between bioenergy and CCS, especially in ambitious climate change mitigation scenarios. This is a result of BECCS becoming costcompetitive at sufficiently high carbon prices due to increasing final energy prices and, more importantly, the revenue associated with carbon dioxide removals. We explore the bioenergyCCS nexus for different carbon budgets by looking at both the share of bioenergy coupled to CCS and the share of CCS technologies fueled with biomass (Fig. 7). For the near future, models consistently project lower shares of CCS coupled to biomass and much of the biomass use is not combined with CCS (Fig. 7). Over time, however, the nexus between bioenergy and CCS strengthens, and both shares increase significantly. The former insight validates the findings from Rose et al. (2014). Overall, results show that bioenergy becomes the preferred fuel for CCS technology as the carbon price increases (moving forward in time or for more stringent scenarios). Similarly, the share of bioenergy that is coupled to CCS technologies increases as the carbon price increases since BECCS effectively enhances the emissions mitigation capacity of bioenergy, by capturing and storing the carbon that is typically emitted when biomass is converted to final energy carriers (e.g., electricity or liquid fuels). In other words, each joule of bioenergy transformed to a final energy carrier with CCS is up to twice as
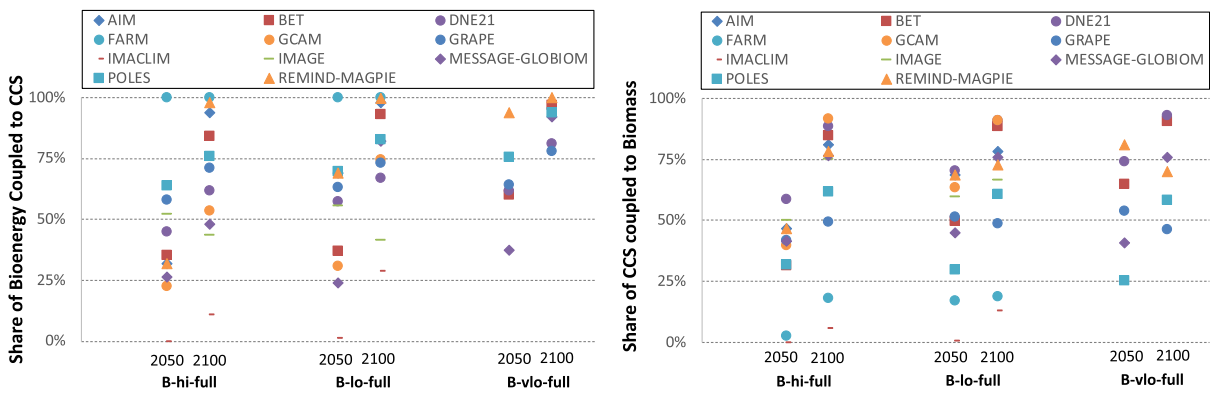

Fig. 7 Bioenergy-CCS nexus: share of primary bioenergy coupled to CCS and share of CCS coupled to biomass 
effective in emissions mitigation as one without CCS (Muratori et al. 2016). While these trends are in general consistent across all models, the absolute magnitude of the bioenergy-CCS nexus varies significantly between models (as well as the overall role of BECCS in future energy systems, as shown in Fig. 2). Models that could not solve for the B-vlo-full target generally show lower shares of bioenergy coupled to CCS and of CCS coupled to biomass in the B-lo-full scenario, as shown in Fig. 7.

\section{Conclusions}

Several studies have concluded that the availability of BECCS technologies makes it easier and less expensive to achieve stringent climate goals. Using multiple models and standardized scenarios, including ambitious climate change mitigation and bioenergy specific sensitivity scenarios, we directly and more comprehensively explore the potential for BECCS, providing much needed transparency and comparability regarding a technology that may impact the pursuit of ambitious international $1.5{ }^{\circ} \mathrm{C}$ and $2{ }^{\circ} \mathrm{C}$ climate goals.

The EMF-33 scenarios presented in this paper, generated from a broad set of global models considering consistent climate change mitigation goals and bioenergy technology sensitivity scenarios, validate past high-level insights, and contribute additional understanding on the potential role of BECCS in future energy systems and climate management strategies:

a. Models disagree on the exact role of BECCS in future energy systems, but agree on its importance, especially to reach scenarios considering a $400 \mathrm{Gt} \mathrm{CO}_{2}$ budget, which is consistent with limiting warming to $1.5^{\circ} \mathrm{C}$. BECCS is found to be essential, with all models unable to meet the climate goal without BECCS (noting that no other CDR technology is considered in this study).

b. BECCS could be deployed across multiple sectors. While many models only include BECCS technologies in the electricity sector, models in which BECCS is allowed across multiple sectors show significant use of BECCS for liquid fuel or hydrogen production as a solution to decarbonize the transportation sector. However, BECCS deployment in the electricity sector is less sensitive to carbon prices compared with the liquid fuels sector.

c. Models show limited sensitivity in BECCS deployment to uncertainties in BECCS technology cost and availability timing: higher BECCS technology costs or delayed technology availability postpone BECCS adoption but do not significantly change the ultimate deployment of BECCS in the long-run.

d. Investment decisions in IAMs are based on a number of factors. In particular, for BECCS technologies, cost is an important determinant of deployment but not the only one. A number of other factors influence BECCS utilization across sectors, including transitional and system integration factors, as well as market dynamics such as fuel and biomass feedstock costs, the relative elasticity of demand for different energy services, the availability and costs of alternative mitigation options, and other modeling constraints that shape the transformations that can take place in the energy mix.

e. Models show sensitivity in the timing and rate of BECCS deployment to climate change mitigation goals but limited sensitivity in its ultimate deployment. Scenarios with more stringent climate targets typically show earlier and more rapid BECCS deployment but not necessarily greater use overall. The extent of ultimate BECCS deployment varies based on 
model assumptions, but most models rely on BECCS for $15 \%$ or more of total primary energy use in the long run.

f. BECCS deployment is limited by physical limitations (land use, carbon storage) and economic competition with other carbon-free technologies, especially in the electricity sector, which affect bioenergy availability and price.

g. Models show a strong nexus between CCS and biomass: bioenergy becomes the preferred fuel for CCS technology as the carbon price increases (moving forward in time or for more stringent scenarios). Similarly, the share of bioenergy that is coupled to CCS technologies increases as the carbon price increases since BECCS effectively enhances the emissions mitigation capacity of bioenergy.

While models show great reliance on BECCS technologies, it is important to keep in mind that these technologies are not commercially available today, and the viability and economic consequences of large-scale BECCS deployment, including regional, institutional, and technical limitations, are not well understood. Reliance on BECCS could be reduced by the availability of other CDR options, such as afforestation or direct air carbon capture and storage. Given the significant role of BECCS demonstrated in this study to meet carbon mitigation targets (especially consistent with a $400 \mathrm{Gt} \mathrm{CO}_{2}$ budget for which BECCS is shown to be essential), BECCS should be the focus of detailed modeling and feasibility studies and R\&D investments should be focused toward improving availability and performance of bioenergy technologies, assess their sustainability, and developing solutions to effectively integrate them into energy systems and global business models.

Acknowledgments The authors would like to thank Kara Podkaminer and two anonymous reviewers for useful comments. The views expressed in this paper are those of the individual authors and do not necessarily reflect those of the author's institutions or funders. This research was partially supported by the intramural research program of the U.S. Department of Agriculture, Economic Research Service. The findings and conclusions in this publication are those of the authors and should not be construed to represent any official USDA or U.S. Government determination or policy, or the views of any of the institutions associated with this study's authors.

\section{References}

Azar C, Lindgren K, Obersteiner M, Riahi K, van Vuuren DP, den Elzen KMG, Möllersten K, Larson ED (2010) The feasibility of low $\mathrm{CO}_{2}$ concentration targets and the role of bio-energy with carbon capture and storage (BECCS). Clim Chang 100(1):195-202

Azar C, Johansson DJ, Mattsson N (2013) Meeting global temperature targets - the role of bioenergy with carbon capture and storage. Environ Res Lett 8(3):034004

Bauer N et al (2018) Global energy sector emission reductions and bioenergy use: overview of the bioenergy demand phase of the EMF-33 model comparison. Clim Chang:1-16

Bauer N, et al. (2020) "Bio-energy and CO2 emission reductions: an integrated land-use and energy sector perspective". This issue

Bui M, Adjiman CS, Bardow A, Anthony EJ, Boston A, Brown S, Fennell PS et al. (2018) Carbon capture and storage (CCS): the way forward. Energy Environ Sci 11(5):1062-1176

Calvin K, Edmonds J, Bond-Lamberty B, Clarke L, Kim SH, Kyle P, Smith SJ, Thomson A, Wise M (2009) 2.6: Limiting climate change to $450 \mathrm{ppm} \mathrm{CO}_{2}$ equivalent in the $21^{\text {st }}$ century. Energy Econ 31:S107-S120

Clarke LE, Jiang K, Akimoto K, Babiker M, Blanford GJ, Fisher-Vanden K, Hourcade JC, Krey V, Kriegler E, Loschel A, McCollum D (2014) Assessing transformation pathways. In: Climate Change 2014: mitigation of climate change. Contribution of Working Group III to the Fifth Assessment Report of the Intergovernmental Panel on Climate Change

Daioglou et al. (2020) Bioenergy technologies in long-run climate change mitigation: results from the EMF33 study. This Issue 
Edmonds J, Luckow P, Calvin K, Wise M, Dooley J, Kyle P, Kim SH, Patel P, Clarke L (2013) Can radiative forcing be limited to $2.6 \mathrm{Wm}-2$ without negative emissions from bioenergy AND CO2 capture and storage? Clim Chang 118(1):29-43

Fuss S, Canadell JG, Peters GP, Tavoni M, Andrew RM, Ciais P, Jackson RB, Jones CD, Kraxner F, Nakicenovic N et al (2014) Betting on negative emissions. Nat Clim Chang 4(10):850-853

Fuss S, Lamb WF, Callaghan MW, Hilaire J, Creutzig F, Amann T, Beringer T, de Oliveira Garcia W, Hartmann J, Khanna T, Luderer G (2018) Negative emissions - Part 2: Costs, potentials and side effects. Environ Res Lett 13(6):063002

Gasser T, Guivarch C, Tachiiri K, Jones C, Ciais P (2015) Negative emissions physically needed to keep global warming below $2^{\circ} \mathrm{C}$. Nature Commun $6(1): 1-7$

Kemper J (2015) Biomass and carbon dioxide capture and storage: a review. Int J Greenhouse Gas Control 40: $401-430$

Klein D, Luderer G, Kriegler E, Strefler J, Bauer N, Leimbach M, Popp A, Dietrich JP, Humpenöder F, LotzeCampen H, Edenhofer O (2014) The value of bioenergy in low stabilization scenarios: an assessment using REMIND-MAgPIE. Clim Chang 123(3-4):705-718

Koelbl BS, van den Broek MA, Faaij AP, van Vuuren DP (2014) Uncertainty in carbon capture and storage (CCS) deployment projections: a cross-model comparison exercise. Clim Chang 123(3-4):461-476

Leblanc F, et al. (2020) "The contribution of bioenergy to the decarbonization of transport in EMF-33". This Issue

Muratori M, Calvin K, Wise M, Kyle P, Edmonds J (2016) Global economic consequences of deploying bioenergy with carbon capture and storage (BECCS). Environ Res Lett 11(9):095004

Muratori M, Smith SJ, Kyle P, Link R, Mignone BK, Kheshgi HS (2017a) Role of the freight sector in future climate change mitigation scenarios. Environ Sci Technol 51(6):3526-3533

Muratori M, Kheshgi H, Mignone B, Clarke L, McJeon H, Edmonds J (2017b) Carbon capture and storage across fuels and sectors in energy system transformation pathways. Int J Greenhouse Gas Control 57:34-41

National Academies of Sciences, Engineering, and Medicine (2018) "Negative emissions technologies and reliable sequestration: a research agenda." Negative emissions technologies and reliable sequestration: a research agenda

Rogelj J, Luderer G, Pietzcker RC, Kriegler E, Schaeffer M, Krey V, Riahi K (2015) Energy system transformations for limiting end-of-century warming to below 1.5 [deg] C. Nat Clim Chang 5(6):519-527

Rogelj J, et al. (2018) Mitigation pathways compatible with $1.5^{\circ} \mathrm{C}$ in the context of sustainable development

Rose SK, Kriegler E, Bibas R, Calvin K, Popp A, van Vuuren DP, Weyant J (2014) Bioenergy in energy transformation and climate management. Clim Chang 4:477-493

Rose S et al. (2020) "Global biomass supply modeling for long-run management of the climate system" This Issue

Sanchez DL, Kammen DM (2016) A commercialization strategy for carbon-negative energy. Nat Energy 1: 15002

Smith P, Davis SJ, Creutzig F, Fuss S, Minx J, Gabrielle B, Kato E, Jackson RB, Cowie A, Kriegler E, Van Vuuren DP (2016) Biophysical and economic limits to negative $\mathrm{CO}_{2}$ emissions. Nat Clim Chang 6(1):42-50

Strefler J, Bauer N, Kriegler E, Popp A, Giannousakis A, Edenhofer O (2018) Between Scylla and Charybdis: delayed mitigation narrows the passage between large-scale CDR and high costs. Environ Res Lett 13(4): 044015

Tavoni M, Socolow R (2013) Modeling meets science and technology: an introduction to a special issue on negative emissions. Clim Chang 118(1):1-14

van Vliet J, Hof AF, Beltran AM, van den Berg M, Deetman S, den Elzen MG, Lucas PL, van Vuuren DP (2014) The impact of technology availability on the timing and costs of emission reductions for achieving long-term climate targets. Clim Chang 4:559-569

van Vuuren DP, Deetman S, van Vliet J, van den Berg M, van Ruijven BJ, Koelbl B (2013) The role of negative $\mathrm{CO} 2$ emissions for reaching $2 \mathrm{C}$ - insights from integrated assessment modelling. Clim Chang 118(1):15-27

Vaughan NE, Gough C (2016) Expert assessment concludes negative emissions scenarios may not deliver. Environ Res Lett 11(9):095003

Publisher's note Springer Nature remains neutral with regard to jurisdictional claims in published maps and institutional affiliations. 


\section{Affiliations}

Matteo Muratori ${ }^{1} \cdot$ Nico Bauer ${ }^{2} \cdot$ Steven K. Rose $^{3} \cdot$ Marshall Wise $^{4}$.

Vassilis Daioglou ${ }^{5,6}$ - Yiyun Cui ${ }^{4}$. Etsushi Kato ${ }^{7}$ - Matthew Gidden ${ }^{8}$ • Jessica Strefler ${ }^{2}$. Shinichiro Fujimori ${ }^{9,10} \cdot$ Ronald D. Sands $^{11} \cdot$ Detlef P. van Vuuren ${ }^{5,6} \cdot$ John Weyant $^{12}$

\section{Matteo Muratori}

matteo.muratori@nrel.gov

1 National Renewable Energy Laboratory (analysis performed while at Pacific Northwest National Laboratory), Golden, CO, USA

2 Potsdam Institute for Climate Impact Research (PIK), Potsdam, Germany

3 Electric Power Research Institute (EPRI), Washington, DC, USA

4 Pacific Northwest National Laboratory - Joint Global Change Research Institute, College Park, MD, USA

5 PBL Netherlands Environmental Assessment Agency, The Hague, the Netherlands

6 Copernicus Institute of Sustainable development, Utrecht University, Utrecht, the Netherlands

7 Institute of Applied Energy, Minato, Tokyo, Japan

8 International Institute for Applied Systems Analysis (IIASA), Laxenburg, Austria

9 Department of Environmental Engineering, Kyoto University, C1-3-361, Katsura-Campus, Nishikyo-ku, Kyoto-City, Japan

10 Center for Social and Environmental Systems Research, National Institute for Environmental Studies (NIES), 16-2, Onogawa, Tsukuba, Japan

11 U.S. Department of Agriculture, Economic Research Service, Washington, DC, USA

12 Stanford University, Palo Alto, CA, USA 